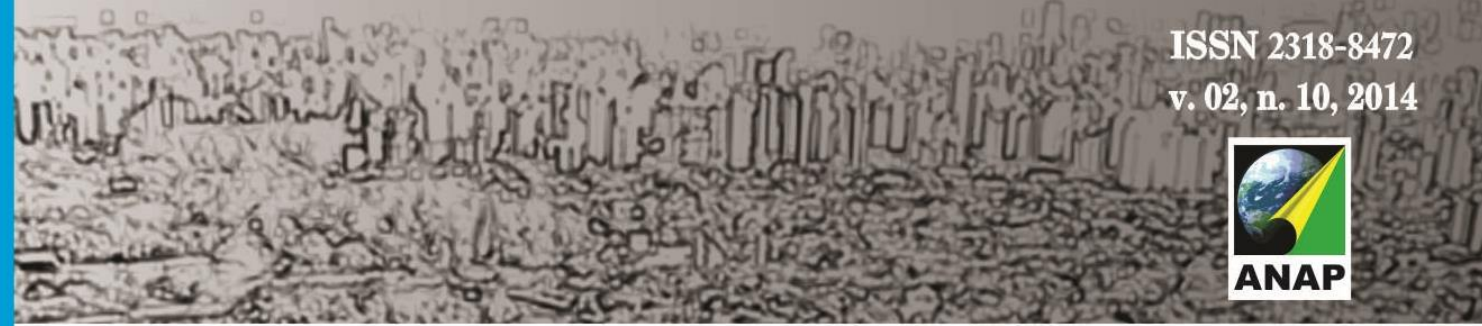

Revista Nacional de

Gerenciamento de Cidades

\title{
GESTÃO DE RESÍDUOS SÓLIDOS URBANOS EM MOÇAMBIQUE, RESPONSABILIDADE DE QUEM?
}

\author{
José Maria do Rosário Chilaúle Langa ${ }^{1}$
}

\begin{abstract}
RESUMO
Em Moçambique, particularmente na cidade de Maputo a Gestão de Resíduos Sólidos Urbanos, é uma realidade (mesmo sendo tardia e pouco funcional) os projetos que são desenvolvidos pelo Município (poder público), tendo participação de organismos não governamentais. Na sua maioria é possível ter benefícios sociais, ambientais e econômicos da GRSU. A Educação Ambiental é tida como fundamental, pois permite a integração dos vários atores, sendo eles do poder público e produtores. Este texto apresenta o cenário da responsabilização dos vários atores na GRSU em Moçambique, tendo como caso a cidade de Maputo. Com base em pesquisa bibliográfica, documental e visitas técnicas em empreendimentos (Recicla, Fertiliza, ComSol, Amor e Pagalata) foi elaborado este texto. De modo geral, estes projetos iniciativas positivas, embora sua contribuição ainda seja pouco considerável nos três setores: social, ambiental e econômico, para muitos já demonstram uma possibilidade de ação. Parta chegar a integração que se refere no texto precisa mudar de postura dos vários atores, sem essa mudança não se chegará para a gestão integrada, por exemplo a falta de estrutura, falta de financiamentos, reduzida sensibilização, falta de formação, daí que, acreditamos na construção coletiva desta GRSU na cidade de Maputo, buscando atender as questões especificas dela.
\end{abstract}

PALAVRAS-CHAVE: Resíduos Sólidos, Responsabilidade, Moçambique

\section{SOLID WASTE MANAGEMENT IN MOZAMBIQUE RESPONSIBILITY TO WHOM?}

\begin{abstract}
In Mozambique, particularly in the city of Maputo Municipal, the Solid Waste Management, is a reality (even being late and barely functional) projects that are developed by the municipality (public power), with participation of non-governmental organizations. Most can have social, environmental and economic benefits of GRSU. Environmental education is considered essential because it allows the
\end{abstract}

\footnotetext{
${ }^{1}$ Doutorando em Geografia, Unesp - FCT - PPGG. Bolsita CAPES - PEC-PG. Email langajosemaria@hotmail.com
} 


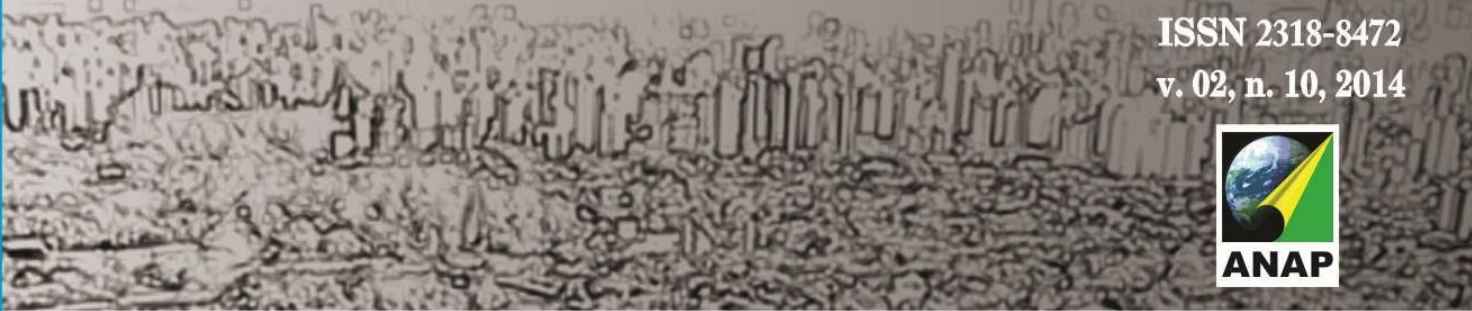

Revista Nacional de

Gerenciamento de Cidades

integration of various actors, the government and producers. This paper presents the scenario of accountability of the various actors in GRSU in Mozambique, and how should the city of Maputo. Based on literature, documentary and technical developments in (Recicla, Fertiliza, ComSol, Amor and Pagalata) visits this research paper was written. In general, these positive initiatives, although its contribution is still some considerable projects in three sectors: social, environmental and economic, for many already show a possibility of action. Depart arrive integration referred in the text needs to change the posture of the various actors, without this change did not reach for the integrated management, for example the lack of infrastructure, lack of funding, low awareness, lack of training, hence, we believe the collective construction of this GRSU in Maputo, seeking to meet the specific questions it.

KEY-WORDS: Solid Waste, Responsibility, Mozambique

\section{GESTIOON DE RESIDUOS SÓLIDOS EM MOZAMBIQUE RESPONSABILIDAD DE QUIÉN.}

\section{RESUMEN}

En Mozambique, en particular en la ciudad de Maputo Municipal de Gestión de Residuos Sólidos, es una realidad (incluso llegar tarde y apenas funcional) los proyectos que se desarrollan por el municipio (poder público), con participación de las organizaciones no gubernamentales. La mayoría puede tener beneficios sociales, ambientales y económicos de GRSU. La educación ambiental se considera esencial, y a que permite la integración de los diferentes actores, a saber, el gobierno y los productores. En este trabajo se presenta el cenario de la rendición de cuentas de los distintos actores en GRSU en Mozambique, y cómo debe la ciudad de Maputo. Con base en la literatura, el documental y la evolución técnica en (Recicla, Fertiliza, ComSol, Amor y Pagalata) visitas este trabajo de investigación fue escrito. En general, estas iniciativas positivas, aunque su contribución es todavía algunos proyectos importantes en tres sectores: sociales, ambientales y económicas, para muchos ya muestran una posibilidad de acción. Partida Arribo integración a que se refiere en el texto tiene que cambiar la postura de los distintos actores, sin este cambio no alcanzó para la gestión integrada, por ejemplo, la falta de infraestructura, la falta de financiación, la escasa conciencia, falta de formación, por lo tanto, creemos la construcción colectiva de este GRSU en Maputo, tratando de responder a las preguntas especificas de ti.

PALABRAS-CLAVE: Residuos Sólidos, Responsabilidad, Mozambique

\section{INTRODUÇÃO}

Falar de Gestão de Resíduos Sólidos Urbanos - GRSU é algo relativamente novo para Moçambique, um país que conquistou sua independência política e administrativa em 1975. Neste artigo abordaremos a questão da GRSU na escala 


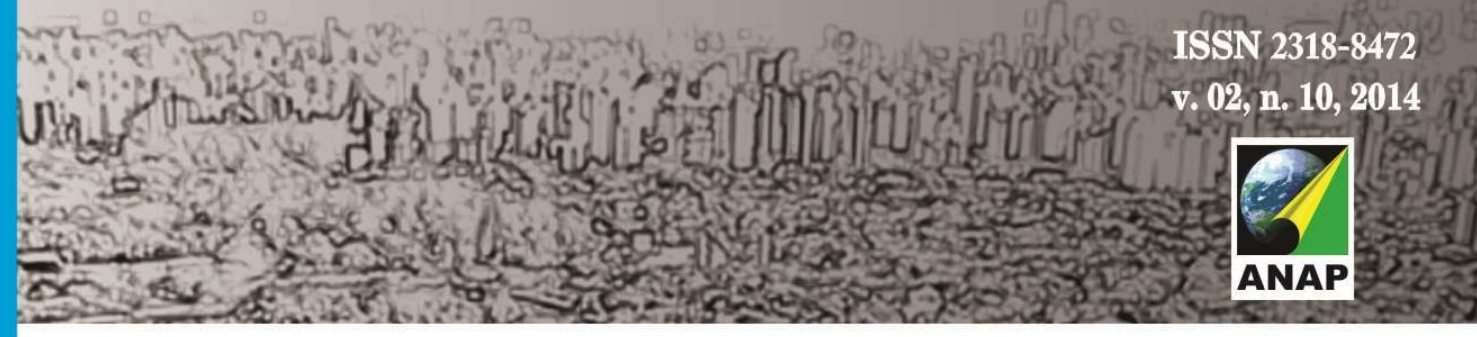

Revista Nacional de

Gerenciamento de Cidades

Segundo Gunther (2008), enquanto as práticas tradicionais tratam de forma parcial o problema dos resíduos, resolvendo-os por meio de afastamento da fonte geradora e da disponibilidade de um local para lançamento dos resíduos no solo, a gestão dos resíduos sólidos vai além dos aspectos operacionais, envolvendo, em uma visão mais abrangente, os demais aspectos relacionados: sociais, econômicos, ambientais e de saúde.

No entanto, o termo que, atualmente, é utilizado como novo paradigma da questão dos resíduos sólidos é gestão integrada.

\begin{abstract}
Entende-se por gestão integrada de resíduos sólidos, o conjunto articulado e inter-relacionado de ações normativas, operativas, financeiras, de planejamento, administrativas, sociais, educativas, de monitoria, supervisão e avaliação para o gerenciamento dos resíduos, desde sua geração até sua disposição final, com o objetivo de obter benefícios ambientais, otimização econômica e aceitação social, respondendo às necessidades e circunstâncias de cada localidade ou região, (Gunther, 2008).
\end{abstract}

O conceito de gestão integrada de resíduos sólidos considera todo o ciclo de produção, consumo, descarte e destino dos resíduos sólidos. O modelo de gestão integrada vai ao encontro do preconizado pela agenda 21: transformação da matriz de produção e consumo, considerando-se o princípio dos 3Rs- reduzir, reutilizar e reciclar.

A coleta seletiva de materiais recicláveis e a reciclagem promovem a redução dos resíduos e a racionalização de sua disposição e contribuem de forma direta com a sustentabilidade urbana e a saúde ambiental e humana, aqui fica mais clara a função ou contribuição dos catadores.

Embora a proposta da legislação moçambicana vise buscar um desenvolvimento sustentável para todos, há de imediato vários interesses em conflito, como, por exemplo, em relação à responsabilização das empresas no destino dos resíduos e a promoção de projetos de coleta seletiva por parte do município (BUQUE,2013 ,p. 41).

Segundo esta autora essa é uma questão que desafia a capacidade de regulação do município na articulação entre interesses privados e coletivos, mas também este assunto de resíduos sólidos abre possibilidades de formulação de 


\section{Revista Nacional de}

contexto do saneamento ambiental e, por sua vez, interagem com as ações de habitação e saúde, resultando em qualidade de vida e desenvolvimento social.

A Lei das Autarquias locais - Lei 2/97, de 18 de Fevereiro, garante aos municípios, competência para a busca do desenvolvimento local com qualidade ambiental, conferida da seguinte forma: a autonomia quanto ao licenciamento ambiental e controle dos impactos ambientais locais; criação e manutenção de parques e áreas verdes; promoção da educação ambiental e planejamento ambiental entre outros.

Á esta lei associam-se mais 5 especificas, que formalmente são complemento da Lei do Ambiente, são elas:

- Regulamento sobre a Gestão de Resíduos Sólidos Biomédicos. - Decreto n.ำ 8/2003, de 18 de Fevereiro.

- Regulamento sobre Inspeção Ambiental - Decreto n.. 11/2006, de 15 de Junho.

- Plano Diretor Gestão de Resíduos Sólidos Urbanos na Cidade de Maputo;

- Postura sobre a Limpeza da Cidade

- Regulamento sobre Gestão de Resíduos Sólidos - Decreto n.ำ 13/2006, de 15 Junho.

Sendo este último o norteador ou mesmo o centro da normalização deste setor que nos propusemos a apresentar neste trabalho.

A consciência de que é necessário integrar à gestão dos resíduos sólidos, é algo que vem surgindo a partir das situações que muitas cidades, vem vivendo, principalmente as africanas, como é o caso de Maputo.

Essa consciência deve colocar a todos como co-responsavéis na GRSU, e que a ação ativa de cada um pode, nos levar a resolver um problema de todos, basta que no mínimo se mudem os comportamentos em relação ao lixo. 


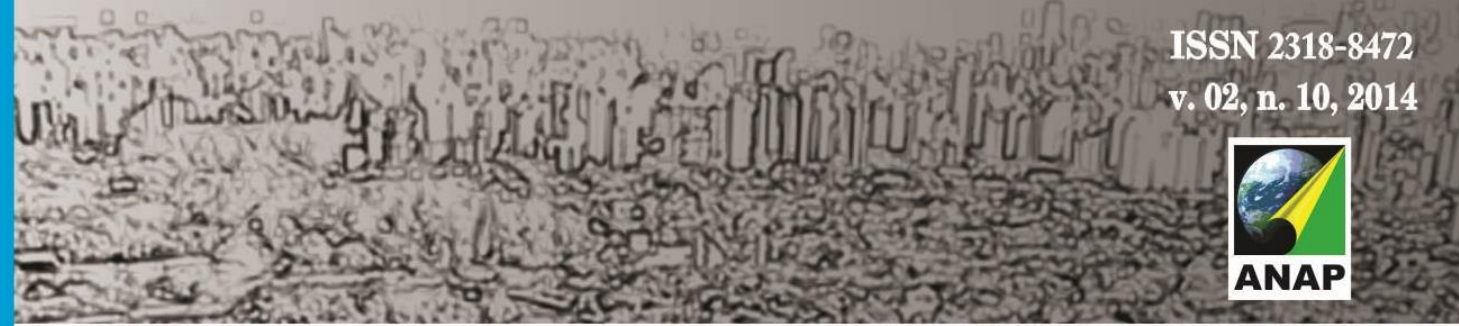

Revista Nacional de

Gerenciamento de Cidades

poderiam ser evitados por meio de maiores investimentos em educação ambiental, coleta, tratamento e disposição final adequada, além de adequadas condições de trabalho para quem lida profissionalmente com os resíduos, como os funcionários dos serviços de limpeza urbana, os catadores e recicladores.

Pensar na integração da GRSU, traz resultados para várias áreas não só para o ambiente, mas para saúde e acima de tudo aumenta a qualidade de vida.

A legislação ambiental é considerada um avanço em Moçambique, onde as grandes cidades (especialmente Maputo) que vem crescendo produzem grandes quantidades de resíduos sólidos por dia, totalmente destinados aos lixões. Entre os aspectos positivos, destaca-se em primeiro lugar, o fato do texto do regulamento sobre gestão de RSU enfatizar o reuso e o reaproveitamento.

\footnotetext{
Uma lacuna das leis é a não referência à participação de associações e ou organizações dedicadas ao beneficiamento e reciclagem de resíduos sólidos. Não há, inclusive, a previsão de financiamento para municípios que façam coleta seletiva com catadores, medida indutora do desenvolvimento das cooperativas/associações de reciclagem (BUQUE, 2013, p. 53).
}

Sendo assim, pode-se dizer que um dos grandes problemas da GRSU é a dificuldade de fazer circular a informação, na medida em que esta claro para todos os atores as suas funções, pelo menos na cidade de Maputo, mas entre estes é fraca ou desarticulada a comunicação, dificultando e perigando esta gestão integrada.

Para Lina Buque a relevância do papel das cooperativas e outras entidades associativas engajadas na minimização e recuperação do volume de resíduos sólidos gerados e na redução dos impactos ambientais a eles associados não está refletida nos diferentes pontos da lei. A lei deveria trazer diversos benefícios para o país, principalmente no tocante à destinação de resíduos, que deveria ser integralmente regularizada num prazo determinado.

Pensar na gênese de responsabilização é acima de tudo pensar no poder público e do gerador de resíduos.

a) gerador do resíduo, o dever de realizar a separação prévia do seu resíduo, oferecendo à coleta os materiais já devidamente segregados e em condições 


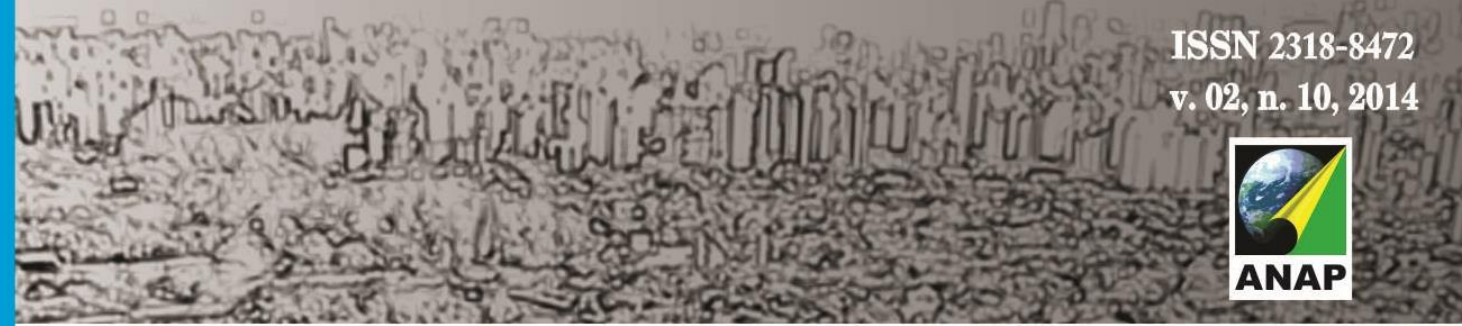

Revista Nacional de

Gerenciamento de Cidades

de ser gerenciado, facilitando o trabalho dos setores formais, responsáveis pelo reaproveitamento ou reciclagem e b) O poder público de modo próprio, ou mediante concessão, deverá providenciar para que os resíduos sólidos tenham reconhecimento, separação, tratamento e destinações adequadas (BUQUE, 2013, p. 54).

Deve ser pensando este sistema como um, e não um sistema de cobranças de responsabilidades, deve o poder público criar condições e informar e formar a comunidade (geradores) e estes por sua vez, ajudarem a dar a vida a estratégia e também controlar o sistema. O controle deve ser responsabilidade de todos no sistema onde o ideal é cada um dos atores ou integrantes considerar-se como autocontrolar.

A geração de resíduos sólidos, nas cidades moçambicanas, é um processo que ocorre diariamente em quantidades e composições que variam conforme seu nível de desenvolvimento econômico e seus diferentes extratos sociais, atividade econômica, localização do bairro, mas principalmente pelo costume e hábitos dos munícipes, daí que é necessário na GRSU pensar na Educação Ambiental, exatamente para mudar o que historicamente se pensou sobre os resíduos sólidos, a coleta e $o$ afastamento destes, que se materializa na deposição final.

Esta forma de pensar (afastar os resíduos) foi repetida sistematicamente pelo poder público representado pelos Conselhos Municipais, quando a partir de escolhas logísticas, tais como o aumento da frota de caminhões, a ampliação do número de funcionários e a melhoria do sistema de disposição final e a comunidade enterrando o lixo nas áreas de suas casas ou depositando com contentores, desligando se totalmente deste, como se a GRSU fosse somente responsabilidade do poder público.

Hoje, com o debate sobre os problemas ambientais e a valorização de resíduos no mercado impulsionou uma série de novos atores, públicos e privados, atraídos pelo valor dos materiais recicláveis, como falamos no início deste texto ações de coleta seletiva e reciclagem, ganham espaço para resolver problemas ambientais, sociais e econômicos. É dentro desse triangulo de fatores que os projetos de reciclagem e coleta seletiva foram pensados em Maputo. Cinco são os 


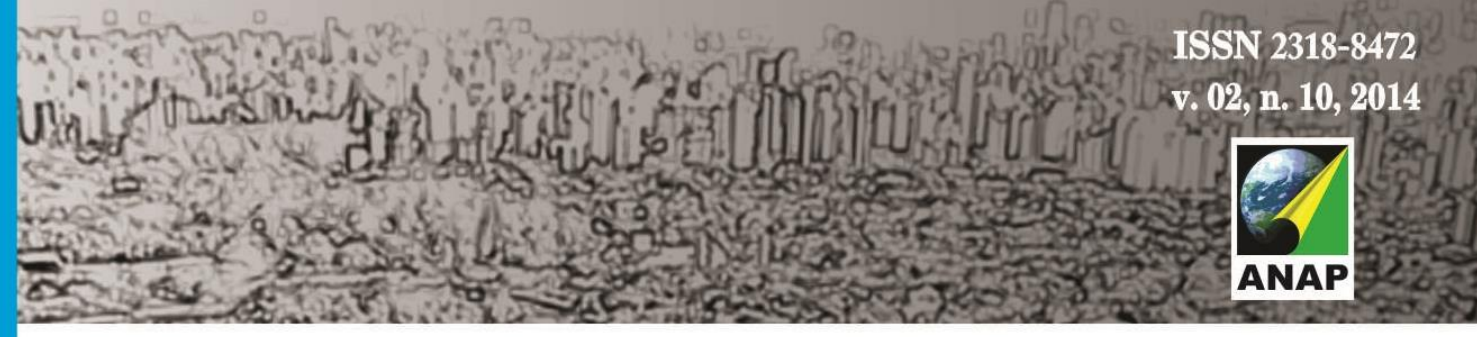

Revista Nacional de

Gerenciamento de Cidades

Os projetos acima indicados foram implantados e apoiados pelo município como estratégia de envolvimento da população com políticas ambientais. Segundo Buque (2013) a baixa abrangência e divulgação dos projetos mostra que há um fraco relacionamento entre as organizações e o município.

Esta percepção de fraco relacionamento é algo que periga os projetos, a falta de comunicação. Para o município estes projetos não são do município, pois estes surgem para responder suas demandas, uns mais sociais, outros mais econômicos mas todos com atividades nas aeras ambientais por conta disso o município apoia, o que no meu ver denuncia a falta o reconhecimento do papel destas cooperativas e associações na GRSU, por parte do município. Estas instituições deveriam ser pagas pelo seu trabalho na cidade, como são pagas as empresas de recolha que 0 município contrata.

Os cinco projetos têm uma relação muito forte com os catadores, daí que é necessário conhecer melhor estes novos atores, na GRSU.

\footnotetext{
Segundo Mertanen, Langa e Ferrari (2014, p. 45) o fenômeno da forte presença de catadores nas ruas da cidade de Maputo é fundamentalmente um problema social: exclusão, pobreza, doenças, deficiência e vários tipos de vulnerabilidade levando estas pessoas a viver à margem da sociedade, sustentando a si próprios e às suas famílias com os lixos produzidos pelas outras pessoas "socialmente integradas".
}

Para estes autores e necessário que se valorize este trabalho, juntamente com ações de integração social e educacional, pois estas áreas contribuem para capitalização de reabilitação humanas destes catadores.

Sendo assim, é necessário reconhecer estes atores na gestão formal de resíduos sólidos, pois dessa forma desperta-se a sua importância neste setor mas ao mesmo tempo se aumenta a auto estima deste grupo. Mertanen, Langa e Ferrari (2013, p. 45).

Este reconhecimento permitirá maior aceitabilidade de destes e outros atores e produzirá efeitos na cidade, aumentando de atores na GRSU. 


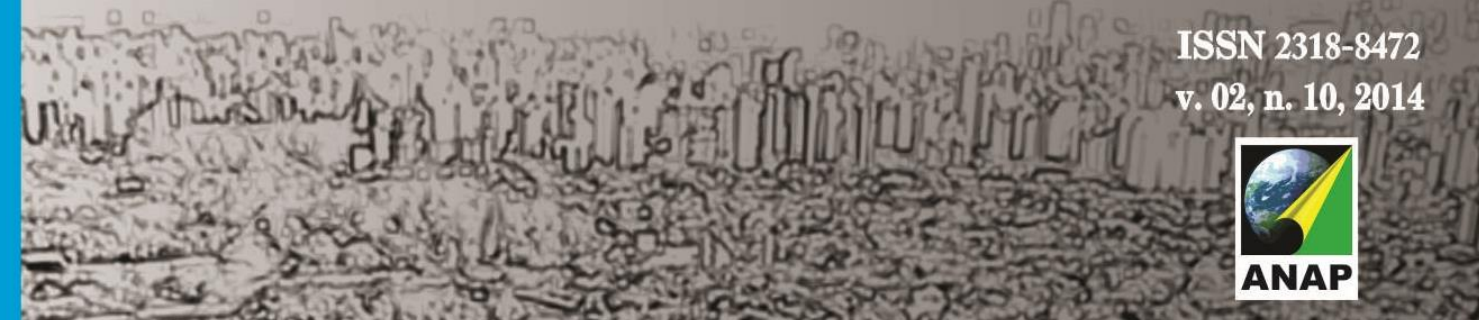

Revista Nacional de

Gerenciamento de Cidades

\section{CONCLUSÃO}

Com a integração da GRSU, cria-se uma base estrutural que responde não só aos problemas do ambiente, mas atende aos problemas sociais, como é o caso de inserção de catadores no sistema formal de gestão de resíduos.

Em Maputo, as associações e cooperativas estão ganhando território e protagonismos na área de GRSU, concretamente no que diz respeito á coleta seletiva e reciclagem.

A leis sobre GRSU, já existem, daí que existem responsabilidade para cada aos neste setor, mas um dos fatores que periga a GRSU é a educação, esta possibilitará a mudança de hábitos e costumes da comunidade em relação ao lixo.

Segundo Buque (2013) deve ser clara a separação responsabilidades entre o gerador e o poder públicos, sendo: a) gerador do resíduo, o dever de realizar a separação prévia do seu resíduo, oferecendo à coleta os materiais já devidamente segregados e em condições de ser gerenciado, facilitando o trabalho dos setores formais, responsáveis pelo reaproveitamento ou reciclagem e b) o poder público de modo próprio, ou mediante concessão, deverá providenciar para que os resíduos sólidos tenham reconhecimento, separação, tratamento e destinações adequadas (p. 54).

Desta forma é que esta sendo construída a GRSU na cidade de Maputo, mesmo esta não sendo compreendida por todos os atores, mesmo sem o poder público ter uma estrutura capaz de suportar as demandas dessa GRSU.

A responsabilidade na GRSU é de todos, pois não adianta o poder público ter estrutura se a comunidade não esta educada e formada para GRSU, o mesmo se for o inverso.

\section{REFERÊNCIAS}


